\title{
HISTOMORPHOMETRIC STUDY OF DENTAL CEMENTUM AND CORRELATION OF CEMENTAL INCREMENTAL LINES WITH AGE IN EGYPTIANS
}

\author{
'bY \\ Neven Almed Hassan and Amal A. Shehab": \\ Departments of lorcnsic Mladicinc and Clinical Toxicology \& Anatoniy' and Limbryology"*, \\ Faculty of Aledicine, Tanta Unicrsity, Egypt
}

\begin{abstract}
Age determination of an individual is necessary for idcntification in physical anthropology; bioarchacology and forensic sciences. Gradual structural changes in feeth throughout life are the basis for age estimation. Dental cementum shows variable mumber of alscrnating ligh. and dark bands referred as incremental lines. So the aim of this research wers to study the histology of human dental ccmentum and to evaluate the correlation between chronological age and the number of cemental incremental lines. Eighty w'o mandibular first premolar tecth of known age and sex were collected and fixed in 10\% formal-saline. Twelve teeth were secrioncel using the diamond saw with 100 um thickness. Serenty tecth were decalcified in EDTA for 3-5 months, dehydrated and ambedded in paruffin. 5-7 un thick sections were staincd with Hacmato.yyline \& Eosin, 1 \% Alizarin red and Cresyl Fast Violet stains. The un-decalcified ground sections were photographed. The widh of the cemcntum was measured with Vernier caliper in each photomicrograph at .140 magnificaition. Also, all stained decalcified scctions 1 'ere photographed at $x 200$. For each photomicrograph measurcment of the widh occupied by wo clearly visible adjacent incremental lines and measurement of the widh of the cementum nere taken using Vernicr caliper. The theoretical number of incremental lines in the total cementum width was calculated. Biological age was estimated by summing up the calculatcd mumber of incremental lines and the arerage age of tooth. All recorded results were used in statistical analysis. The mean and standard deviations of dental age, the arerage difference from chronological age were calculatcal. Pearson's correlation cocfficient (r) was calculated betwecn dental age, number of calculated lines, chronological age and cementum in different age groups. Linear regression was used to find the relation between chronological age and number of calculatcd iatremental lines. Ground sections of different ages revealed noticeable different thickness of the cementum. The cementum was surrounded externally by bundles of periodontal ligament and internally by the root dentinc. Three lajers were encountered; first calcificd cementum, nc.vt a strip of cementoid, and finally' a layer of cementoblasts. Two kinds of cementum were differentiated: cellular and accllular. Spiderlike cementocy)tes were incorporated within cellular cementum and they were best vieved in un-dlecalcificd ground sec-
\end{abstract}


tions. Acellular cementum slowed alternating wide pale staining bands omd narrow dark staining incremental lines which were better seen in decalcified stained sections. Alectuge crror was 3.17 years among joung individuals but, it becomes higher anong chers, there wers thigh correlation between chronological age, thickness of ccmentum, llic number of incrementel lines and estimated age. Factor of sex has no significant influence on the mumber of lines. There were no statistical differences betnecn males and females regarding the thickness of cementum. It is concluded that counting the incremental lines from dental root cementum represents a very adiantageons, quamitutive method for individual age estimation in humans especially in very fragmentary skeletons.

\section{INTRODUCTION}

Age determination of an individual is necessary for individual identificalion in physical anthropology, bioarchaeology and forensic sciences. Dentition is the most durable and a very informative system. Many age determination methods are based on teeth. An entire set of age determination methods has been elaboraledboth macroscopic and microscopic (Roesing and Kvaal, 1998; Jankauskas ct al., 2001).

Study of leeth to estimate the age of adult human beings is widely accepled in forensic medicine. The bodies of victims of violent crimes, fires, and molor vehicle accidents can be disfigured to such an extent that identification by a family member is neither reliable nor desirable. Persons who have been deceased for some lime prior to discovery and those found in walcr also present unpleasant and difficult visual identifications. Dental identifications have always played a key role in nalural and man-made disaster situations and in par- ticular the mass casualties normally associated wilh aviation disasters. Gradual structural changes in teeth throughout life are the basis for age estimation (Azorit et al., 2002).

Cementum is the mineralized hard dental tissue covering the anatomic roots of human teeth. It begins at the cervical portion of the tooth at the cementoenamel junction and continues to the apex. It is a specialized avascular connective tissue. It is deposited in layers throughout life. Cementum contains about $45 \%$ to $50 \%$ inorganic substances in the form of calcium and phosphate and $50 \%$ to $55 \%$ organic malerial in the form of collagen and protein polysaccharides. Under normal conditions grorvth of cementum is a rhythmic process, and as a new layer is formed, the old one calcifies (Bhaskar, 1991; Rao and Rao, 1998). By light microscope, the root cementum of human teeth and of some animals shows a variable number of allernating light and dark concentric bands referred as incremental lines or annulations. These lines are assumed to be added year- 
ly (Renz et al., 1997; Rao and Rao, 1998).

The main function of the cementum is to furnish a medium for the attachment of the tooth to alveolar bone. As the most superficial layer of cementum ages, a new layer must be deposited to keep the attachment apparatus intact. The repeated apposition of cemental layers represents aging of the tooth as an organ. This physiological process leads to deposition of cementum in alternating transparent and opaque bands (Charles et al., 1986; Bhaskar, 1991; Kolltveit et al., 1998; Kagerer and Grupe, 2001).

So the aim of this research was to study the histology of human dental cementum and to evaluate the correlation between chronological age and the number of incremental lines. A further aim was to find a formula from which the age can be calculated using regression analysis.

\section{MATERIAL AND METHODS}

The material consisted of 82 mandibular first premolar teeth of known age and sex collected by clinical extraction from the Oral Surgery Clinics of Tanta University. Tooth identification, sex, and date of extraction were obtained from patients' dental records. Chronological age was known through personal identification. Reasons for tooth extraction were mainly due to prosthetic and orthodontic causes.
Teeth were extracted from 41 females and 41 males taking care not to disrupt the cementum. The chronological age of the individuals ranged from $20-80$ years. The extracted teeth were immediately fixed in 10 $\%$ formal-saline. For each tooth the middle one third of the root was chosen for histological examination and analysis according to Charles et al. (1986) and Rao and Rao (1998).

\section{Preparation of un-decalcified ground} sections:

Twelve formal-saline fixed premolar teeth (6 females and 6 males) aged 20, 50 and 80 years ( 4 teeth for each age) were washed in running tap water for several hours to remove excess preservative. For each tooth, both longitudinal and transverse sections from the middle third of the root were done using the diamond saw of the Lica SP 1600 microtome Montasupal. The thickness of each section was $100 \mathrm{um}$. Each section was washed under a weak stream of tap water, polished and cleaned in an ultrasonic bath for 30 seconds, dried on filter paper for 20 minutes and mounted on a slide with Canada balsam according to Naylor et al. (1985) and Jankauskas et al. (2001).

\section{Preparation of decalcified (demineral-} ized) sections:

Seventy formal-saline fixed premolar (35 females and 35 males) teeth aged 20, $30,40,50,60,70$ and 80 years (ten teeth for 
each age) were decalcified in EDTA for 3-5 months. Following decalcification, each tooth was either divided longitudinally into two approximately equal halves in the bucco-lingual plane or transversely at the middle one third of the root. The specimens were dehydrated and embedded in paraffin with good orientation of the cut surface. Longitudinal or transverse sections, 5-7 um thick, were cut from each tooth, mounted and stained with Haematoxyline \& Eosin, $1 \%$ Alizarin red and Cresyl Fast Violet stains according to the routine procedures (Drury and Wallington, 1980; Horobin and Bancroft, 1998).

The un-decalcified ground sections were evaluated under light microscopy and ideal areas were selected and photographed at $\times 40, \times 100$ and $\times 200$. The width of the cementum was measured with Vernier caliper in each photomicrograph at x40 magnification. Also, all stained decalcified sections were evaluated and photographed at $\times 200$ where the incremental lines were easiest to be seen (Naylor et al., 1985; Kvaal and Solheim, 1995). For each photomicrograph, measurement of the width occupied by two clearly visible adjacent incremental lines and, on the same level, measurement of the width of the cementum from dentino-cementum junction to the surface of the cementum were taken using Vernier caliper. It was important to note that the junction was not be consid- ered when measuring the cementum as pointed by Thome and Geiger (1997). The theoretical number of incremental lines in the total cementum width was calculated and recorded.

Biological age was estimated by summing up the calculated number of incremental lines and the average tooth age in years (at which the root is supposed to have reached maximum length) has been taken as a starting point (14 year for males and 13 year for females) (Kvaal and Solheim, 1989; Stein and Corcoran, 1994; Rao and Rao, 1998; Jankauskas et al., 2001). All recorded results were used in statistical analysis.

\section{Statistical analysis:}

The collected data was organized, tabulated and statistically analyzed using software statistical computer package version 12. For quantitative data; the mean and standard deviations of dental age, and the average difference from chronological age were calculated. Pearson's correlation coefficient ( $r$ ) was calculated between dental age, number of calculated lines, chronological age and cementum thickness in different age groups. Man-Whitney (Z) test was performed to test the difference between chronological age and dental age in males and females. Linear regression was used to find the relation between chronological age and the number of calculated incremental lines. Significance was adopt- 
ed at $\mathrm{p}<0.05$ for interpretation of results (Petrie and Sabin, 2005).

\section{RESULTS}

\section{Histological results:}

Longitudinal sections revealed that the entire surface of the dental root was covered with a cementum layer of uneven thickness. The cervical part of the root was covered with a thin layer of cementum. Examination and comparison of the ground sections of different ages revealed noticeable different thickness of the cementurn in comparison to each other (Plate I; Figs. 1, 2, \& 3).

Examination of both mineralized and demineralized sections revealed that the cementum was surrounded externally by bundles of collagen fibers of the periodontal ligament and internally by the root dentine (Plate I \& II; Figs. 1, 2, 3 \& 6). The dentino-cementum junction was only clearly seen in ground sections. It was formed of outer thin structureless hyaline layer and inner granular-appearing area (the granular layer of Tomes). Both were tooth's attachment apparatus and cementing cementum to dentin (Plate I; Figs. 1, 3 $\& 4)$. The dentino-cementum junction appeared as a line in stained decalcified sections (Plate II; Fig. 6).

From the dentino-cementum junction outward, three different layers were en- countered; first calcified cementum, next a strip of cementoid, and finally a layer of cementoblasts. The cementoid tissue formed a thin layer on the calcified cemental surface and was lined by cementoblasts. The cementoblasts were located between the inserting fibers of the periodontal ligament. Connective tissue fibers of the periodontal ligament passed between the cementoblasts into the cementum (Plate II; Fig. 8a).

Two kinds of cementum were differentiated: cellular and acellular. The location of cellular and acellular cementum was not definite. Cellular cementum was more frequent on the apical half whereas the acellular cementum predominated on the coronal half of the root. Layers of both might alternate in almost any pattern (Plate I; Figs. 2 \& 3).

Cellular cementum incorporated spiderlike cementocytes enclosed within cementocytic lacunae, with numerous cell processes or canaliculi radiating from their cell bodies and directed preferentially towards the periodontal surface. They were best viewed in un-decalcified ground sections rather than the decalcified stained sections (Figs. 4 \& 5).

Acellular cementum showed two types of alternating light and dark layers with different optical and staining properties. Narrow, dark staining incremental lines 
were separated by wider bands of pale staining cementum. The incremental lines were better seen in decalcified stained sections. They were difficult to be identified in un-decalcified ground sections. So that counting of the incremental lines by the use of decalcified sections of different ages which were stained by different stains as $H$ \& E, Alizarin Red and Cresyl Violet stains was clearly preferable. The counting was made where the lines were most easily recognisable to be counted and there were two definite lines in an area of acellular cementum (Fig. 4 \& Plate II - IV; Figs. 6 - 14). In old age (80 years) the incremental lines at the surface were more easily defined than the deep one (Plate IV; Fig. 12).

\section{Statistical Results :}

The average difference between chronological age and estimated age (dental age) was 5.3 years and the maximum difference -in some cases- exceeded 30 years. Average error was 3.17 years $(10.56 \%)$ among younger individuals (20-40 age group) but the preciseness of the method decreases with age and the error becomes higher among older as it was 21.40 years $(41.56 \%)$ in the age group of $60-80$ (Table 1). There was high correlation between chronological age and each of thickness of cementum $(r=0.901)$, the number of incremental lines $(r=0.887)$ as well as estimated age $(r=0.886)$ respectively (Table 2).
The correlation between estimated age and average number of lines calculated was significant in all age groups at $p=0.001$ but there was no correlation between estimated age and chronological age in the age group of 20-40 years $(\mathrm{r}=0.186)$. On the other hand, the correlation was significant in the age groups above 40 years (Table 3 ).

The scatterplot of chronological age versus average number of incremental lines revealed significant dispersal of data around linear regression line in both males and females (Figs. $15 \& 16$ ).

Factor of sex has no significant influence on the number of lines in the age groups $20-40$ and $60-80$ but it was significant in the age group of 40-60 (Table 4). There were no statistical differences between males and females regarding the thickness of cementum (Table 5).

Comparison between males and females regarding difference between chronological and dental age showed significant difference in the age groups of 40-60 and 60-80 but, it was non significant in the age group of 20-40 (Table 6).

Regression formula was done with the incremental lines were the dependent variables. The most significant regression model was Age $=18.630+$ average num- 
bers of lines (1.384) with standard error of estimate 1.936 years (Table 7).

\section{DISCUSSION}

In forensic sciences, a precise age determination is a necessary requirement for individual identification. Study of the teeth to estimate the age of human beings, whether alive, as corpses or as skeletal remains, is widely accepted in forensic medicine. Teeth can easily be inspected in living people, and may be preserved for a long time after death (Kolltveit et al., 1998; Jankauskas et al., 2001). Recent research indicated that tooth-cementum annulations (TCA) may be used more reliably than other morphological or histological traits of the adult skeleton to estimate age. However, confidence intervals for age estimated by this method have not been available for paleodemographic and forensic applications. The present study addresses this problem, based on large known age samples of teeth (Wittwer-Backofen et al., 2004).

The teeth included in this study were single rooted first premolar teeth which were collected by clinical extraction. Double rooted premolars were avoided as the small narrow roots are difficult to section. Similarly, premolars were preferable to canines because the cementum is noticeably thicker in the canines, which may create an illusion whereby more lines are count- ed in the poorly defined areas than are actually present or possibly due to the greater variation in cementum width in the canines (Charles et al., 1986). Moreover, reasons for tooth extraction in this study were mainly due to prosthetic and orthodontic causes. Various periodontal diseases lead to a reduced number of incremental lines, while teeth with a sufficient nutritional support of their root showed a deviation of the histological age from the known actual age of 2-3 years only (Kagerer and Grupe, 2001).

The present study revealed that the entire surface of the dental root was covered with a cementum layer of uneven thickness. The cervical part of the root was covered with a thin layer of cementum. So that for each tooth, the middle one third of the root was chosen for histological examination and analysis. This is in agreement with Charles et al. (1986) and Rao and Rao (1998), who explained that while the thickness of cementum increases apically, the cellularity of the cementum which complicates assessment of annulations and the number of resorption areas also increase. Whereas near the neck of the tooth, the thinness of the layers inhibits scoring. Therefore, the middle third represents the best compromise among cellularity, layer width, and resorption.

The present data showed that comparison of the ground sections of different 
ages revealed noticeable different thickness of the cementum in comparison to each other. This result is in consistent with Lipsinic et al. (1986) who reported that cementurn thickness increases with age. Solheim (1990) added that the increase in cementurn thickness might give a significant contribution to age assessment as it increases three folds between the age of 11 and 70 years.

The present research demonstrated that, three different layers were encountered; first calcified cementum, next a strip of cementoid, and finally a layer of cementoblasts. Two kinds of cementum were differentiated: cellular and acellular. The location of both was not definite. Cellular cementum incorporated spiclerlike cementocytes enclosed within cementocytic lacunae, with numerous cell processes directed preferentially towards the periodontal surface. They were best viewed in un-decalcified ground sections. Moss-Salentijn and HendricksKlyvert (1990) described the cementum consisted of cementoblasts, cementoid, and fully mineralized tissue. Cementoblasts synthesize collagen and protein polysaccharides, which make up the organic matrix of cementum.

The periodontal ligament is the only source of nutrition for the cementocytes, which receive this nutrition via their processes. Its fibers are embedded in the ce- mentum and serve to attach the tooth to surrounding bone (Bhaskar, 1991). New cementum is deposited throughout life at intervals. When the layer of cementoblasts pauses, a calcified layer of cementum is produced. Since cementum does not undergo any consistent remodeling, it becomes thicker with time. This causes the cementocytes, which are located in the deepest layers of cementum, near the dentino-cementum junction to become slowly deprived of their nourishment and the lacunae became empty. After some cementum matrix has been laid down, calcium and phosphate ions are deposited and mineralization begins (Bhaskar, 1991; Rao and Rao, 1998).

The present study showed that the incremental lines in the acellular cementum were better seen in decalcified sections stained by H \& E, Alizarin Red and Cresyl Violet stains. They were difficult to identify in un-decalcified ground sections. Study by Charles et al., (1986) confirmed that the use of decalcified sections was preferred over thick un-decalcified sections. They suggested that the thickness of the sections was a primary factor contributing to the inaccuracy of the technique. Since it was not possible to transect the root so that the plane of the cementum layers was perfectly perpendicular to the plane of the section, the transmission of light through the specimen potentially created superimposing of many layers, 
thus introducing error. This phenomenon was greatly reduced by the use of thinner decalcified sections. Bhaskar (1991) added that the incremental lines can be seen in decalcified specimens prepared for light microscopy but, they are difficult to identify at the ultra structural level. Moreover, Kvaal and Solheim (1995) explained that cementum apposition takes place in phases due to different rates of formation, resulting in two types of layers with different optical and staining properties. Microscopically, these incremental layers in human teeth are seen to be narrow dark-staining lines which alternate with wide pale-staining bands of cementum. The dark staining lines will be referred as incremental lines and the cementum between each two lines as incremental bands. On the other hand, Kvaal et al. (1996) concluded that incremental lines could be observed in un-decalcified ground sections as well as in decalcified stained sections. They explained that, since incremental lines are not destroyed by acids and stain differently than the remaining cementum, it is likely that they possess an organic structure which differ from the cementum. Meanwhile, Sousa et al. (1999) reported that results obtained from mineralized (un-decalcified) $100 \mathrm{mi}$ cron thick cross sections provided the most countable lines.

As regards counting of the incremental lines in this study, It was not possible to count all the lines in a given cementum width in each stained section so that the theoretical number of the incremental lines in the total cementum width was calculated. This was explained by Lipsinic et al. (1986) and Kvaal and Solheim (1995) who mentioned that the incremental lines in human teeth are numerous and close together to be counted. Some studies have found a strong positive correlation between the number of incremental lines in human teeth and the age, but the reliability of counting lines as a method of age estimation in humans has been questioned by others. The reason for this seemed to be both an uneven affinity for the stains used in different parts of the sections, as well as the close proximity of the lines to each other. It has been claimed that there is a risk of counting accessory lines in the cellular cementum, thereby confusing the count (Miller et al., 1988).

The number of incremental lines calculated was closer to chronological age than the number of lines counted, a result which seemed to indicate that not all the incremental lines were observable by the staining technique employed. Some lines might have been so close together that they could not be separated or it might be too faint to be distinguished. In some sections the first line when observed can be confused with dentino- cementum junction (Azorit et al., 2002). On the contrary, previous studies on cemental annulations 
failed to determine chronologic age in humans from cemental annulation (Miller et al., 1988).

Reference wise, the method of calculation of the biological age which was estimated by summing up the calculated number of incremental lines and the average age of tooth eruption which was the same method used by Kvaal and Solheim (1995) who found high correlation between number of lines calculated and tooth age. However, the data analyzed by Miller et al. (1988) indicated that determining chronologic age in humans from cemental annulations is not possible but Stein and Corcoran (1994) found that quantitation of cementum annuli is a moderately reliable means for age estimation in humans. Moreover, Jankauskas et al., (2001) concluded that the incremental lines rather have a similar use as other methods to yield an individual's chronological age.

The present study indicated that estimates based on the number of incremental lines gave only an inkling of the age for individuals over 50 years while age estimates will be most accurate under 40 years, this is in line with Stein and Corcoran (1994) and Kvaal and Solheim (1995) as their studies indicated that predicted age counts for those over 55 years of age showed greater divergence from actual age than in younger individuals but others have found substantial divergence above 30 years (Condon et al., 1986; Lipsinic et al., 1986). The above finding may be interpreted by high frequency of periodontal disease, caries and necrotic pulpal tissue in the teeth aged above 50 years which affect cemental apposition and may be responsible for the great divergence between chronological age and estimated age (Kvaal and Solheim, 1995).

Inspite of the preciseness of the method used decreased with age, assessment of the method's accuracy indicated by strong correlation between the number of calculated lines and chronological age $(\mathrm{r}=0.887)$. The previous result was proved by Kvaal and Solheim (1995) and the slopes of the results are consistent with a hyposis of annual deposition of cementum rings given a decrease in cementogenesis with increasing age (Condon et al., 1986).

Kvaal and Solheim (1995) found that only incremental line is formed in every other year. However, Kvaal et al. (1996) reported that the distance from one line to the next represents a yearly increment deposit of cementum in many mammals, and counting these lines has been used routinely to estimate the age of the animals. Also, Jankauskas et al. (2001) described these lines as annual deposition. On the other hand, Roesing and Kvaal (1998) mentioned that there are possibilities that some humans appose more than 
one layer every year and in older individuals some layers could be skipped. Times of higher physiological calcium demand as previous pregnancies, skeletal trauma and renal diseases which all have a marked influence on the calcium metabolism manifest themselves in the cementum in the form of hypomineralized incremental lines (Kagerer and Grupe, 2001).

The results of the present study indicated that factor of sex had no significant influence on the number of lines in the age groups of $20-40$ and $60-80$ but it was significant in the age group of 40-60. This is in line with Kvaal and Solheim (1995). On the contrary Condon et al. (1986) found the technique provided significantly better estimates for females than for males.
The study herein found high correlation between thickness of cementum and age, but there is no significant difference between male and female subjects. This result is in contrast with Solheim (1990) who found less cementum in women's teeth and he attributed this result due to small tooth size and weak masticatory force in women. The difference between this study and that of Solheim (1990) can be attributed to the use of apical cementum in Solheim research.

It is concluded that counting of the incremental lines from dental root cementum represents a very advantageous quantitative method for individual age estimation in humans especially in very fragmentary skeletons. 
Table (1): Mean and standard deviation of dental age (estimated age) $\&$ differences from chronological age in different age groups.

\begin{tabular}{|l|c|l|l|l|}
\hline \multirow{2}{*}{$\begin{array}{l}\text { Age } \\
\text { groups }\end{array}$} & \multicolumn{2}{|l|}{ Dental age } & $\begin{array}{c}\text { Difference } \\
\text { from } \\
\text { chronological } \\
\text { age Mean士 } \\
\text { S.D. }\end{array}$ & $\begin{array}{c}\text { Difference } \\
\text { from } \\
\text { chronological } \\
\text { age in } \\
\text { percentage\% }\end{array}$ \\
\hline $20-40$ & 24.21 & S.D. & $-3.17 \pm 6.01$ & 10.56 \\
\hline $40-60$ & 31.15 & 5.27 & $-18.00 \pm 5.27$ & 36 \\
\hline $60-80$ & 51.06 & 8.24 & $-21.40 \pm 5.99$ & 41.56 \\
\hline Total & 33.85 & 12.26 & $-13.00 \pm 9.97$ & 61.95 \\
\hline $\begin{array}{l}\text { Average difference } 5.3 \\
\text { Maximum difference } 33.3\end{array}$ & & & \\
\hline
\end{tabular}

Table (2): Correlation coefficient between chronological age, dental age, number of incremental lines and thickness of cementum. Confidence of all coefficient at $p=0.001$

\begin{tabular}{|l|c|c|c|c|c|c|}
\hline Variables & $\begin{array}{c}\text { Dental } \\
\text { agc }\end{array}$ & Line 1 & Line 2 & Line 3 & $\begin{array}{c}\text { Average } \\
\text { number } \\
\text { of lines }\end{array}$ & $\begin{array}{c}\text { Thickness } \\
\text { of } \\
\text { cementum }\end{array}$ \\
\hline & $\mathrm{r}$ & $\mathrm{r}$ & $\mathrm{r}$ & $\mathrm{r}$ & & \\
\hline Line 1 & 0.834 & & & & & \\
\hline Line 2 & 0.890 & 0.884 & & & & \\
\hline Line 3 & 0.856 & 0.907 & 0.931 & & & \\
\hline Average & 0.887 & 0.964 & 0.967 & 0.975 & & \\
\hline $\begin{array}{l}\text { Thickness of } \\
\text { cementum }\end{array}$ & 0.901 & 0.911 & 0.888 & 0.894 & 0.927 & \\
\hline $\begin{array}{l}\text { Chronological } \\
\text { age }\end{array}$ & 0.886 & 0.834 & 0.890 & 0.856 & 0.887 & 0.901 \\
\hline
\end{tabular}




\section{Hassan \& Shehab}

Table (3): Correlation between dental age and calculated lines $\left(r_{1}\right)$, dental age $\&$ chronological age $\left(r_{2}\right)$ and between dental age and cementum thickness $\left(r_{3}\right)$ in different age groups

\begin{tabular}{|l|l|l|l|l|l|l|l|}
\hline Age groups & Mean & $r_{1}$ & $p$ & $r_{2}$ & $p$ & $r_{3}$ & $p$ \\
\hline $20-40$ & 24.21 & 0.951 & $0.001^{*}$ & -0.186 & 0.309 & 0.203 & 0.266 \\
\hline $40-60$ & 31.15 & 0.996 & $0.001^{*}$ & 0.426 & $0.030^{*}$ & 0.349 & $0.046^{*}$ \\
\hline $60-80$ & 51.06 & 0.998 & $0.001^{*}$ & 0.688 & $0.001^{*}$ & 0.688 & $0.001^{*}$ \\
\hline
\end{tabular}

*Significant

Table (4): Comparison of mean number of incremental lines in both males and females

\begin{tabular}{|l|l|l|l|l|l|l|}
\hline \multirow{2}{*}{$\begin{array}{l}\text { Age } \\
\text { groups }\end{array}$} & \multicolumn{3}{|l|}{ Males } & \multicolumn{2}{l|}{ Females } & \multirow{2}{*}{ t } \\
\cline { 2 - 7 } & Mean & S.D. & Mean & S.D. & & \\
\hline $20-40$ & 10.95 & 1.38 & 10.63 & 1.59 & 0.604 & 0.551 \\
\hline $40-60$ & 20.27 & 6.62 & 16.04 & 3.45 & 2.145 & $0.042^{*}$ \\
\hline $60-80$ & 39.89 & 7.84 & 34.87 & 7.88 & 1.493 & 0.151 \\
\hline
\end{tabular}

*Significant 
Table (5): Comparison of cementum thickness in both sexes

\begin{tabular}{|c|c|c|c|c|c|c|}
\hline \multirow{2}{*}{$\begin{array}{c}\text { Age } \\
\text { groups }\end{array}$} & \multicolumn{2}{|c|}{ Males } & \multicolumn{2}{c|}{ Females } & \multirow{2}{*}{$t$} & \multirow{2}{*}{$\mathrm{p}$} \\
\cline { 2 - 5 } & Mean & S.D. & Mean & S.D. & & \\
\hline $20-40$ & 9.01 & 2.08 & 8.63 & 2.48 & 0.465 & 0.645 \\
\hline $40-60$ & 14.33 & 1.53 & 13.52 & 3.07 & 0.893 & 0.381 \\
\hline $60-80$ & 39.75 & 7.73 & 39.90 & 8.54 & 0.043 & 0.966 \\
\hline
\end{tabular}

*Significant

Table (6): Comparison of absolute difference between chronological age and dental age in both sexes

\begin{tabular}{|l|l|l|l|l|l|l|}
\hline \multirow{2}{*}{$\begin{array}{l}\text { Age } \\
\text { groups }\end{array}$} & \multicolumn{2}{|c|}{ Males } & \multicolumn{2}{c|}{ Females } & Z & $p$ \\
\cline { 2 - 7 } & Mean & S.D. & Mean & S.D. & & \\
\hline $20-40$ & 4.86 & 4.33 & 5.85 & 3.84 & 1.068 & 0.286 \\
\hline $40-60$ & 14.87 & 5.41 & 19.96 & 4.25 & 2.324 & $0.020^{*}$ \\
\hline $60-80$ & 18.45 & 3.36 & 24.94 & 6.67 & 2.254 & $0.024^{*}$ \\
\hline
\end{tabular}

*Significant

Table (7): Regression formula for chronological age using calculated number of incremental lines

\begin{tabular}{|l|cc|}
\hline Regression formula & $\mathrm{R}^{2}$ & $\mathrm{SE}$ \\
\hline $\begin{array}{l}\text { Age }:=18.630+\text { average number of } \\
\text { lines }(\mathbf{1 . 3 8 4})\end{array}$ & 0.787 & 1.936 \\
\hline
\end{tabular}




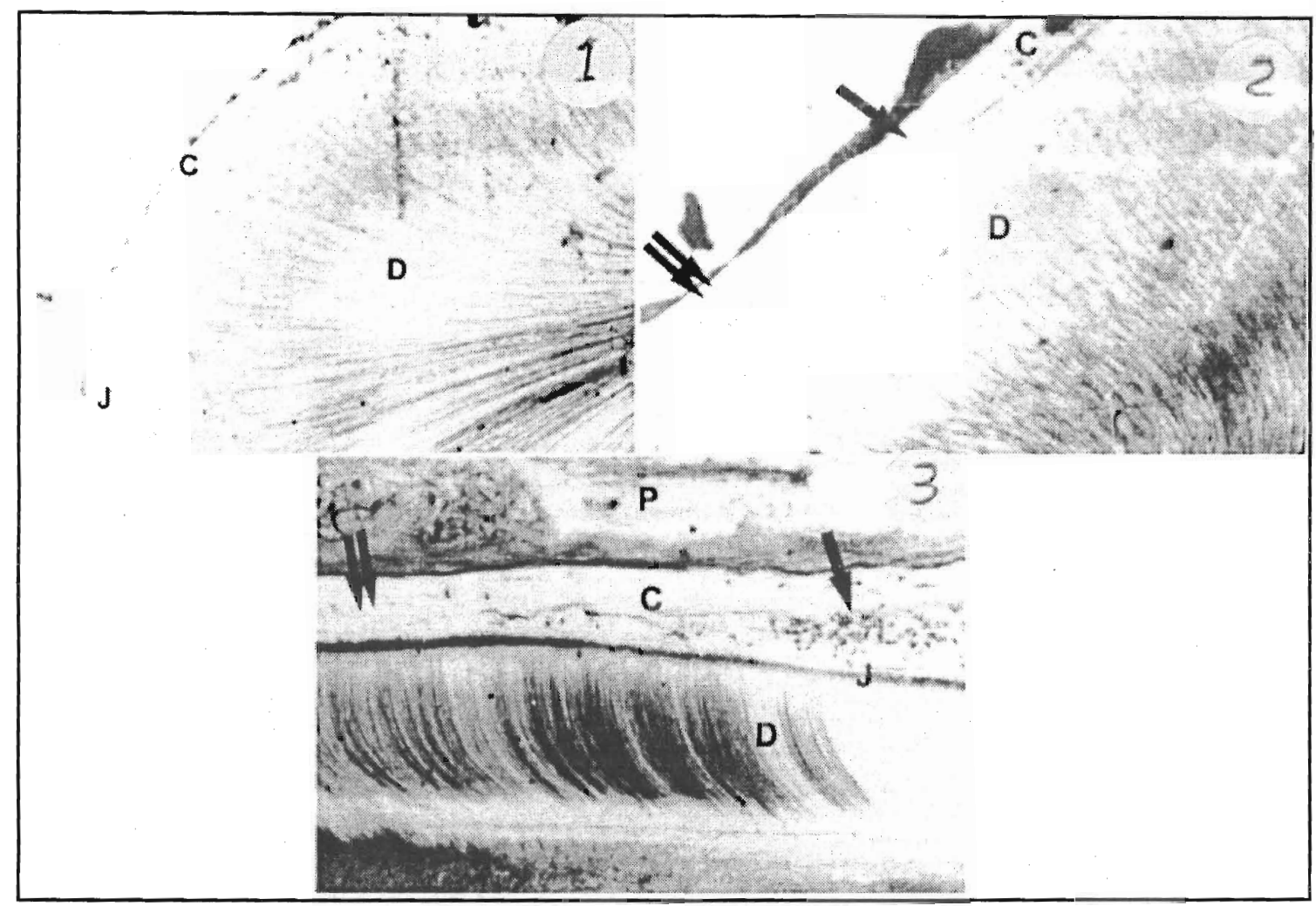

Plate (I): Light photomicrographs of ground sections in mandibular first premolar human teeth of different age groups $(20,50 \& 80)$ showing noticeable different thickness of the cementum $(\mathrm{C})$ in comparison to each other as:

Fig. (1) : Transverse ground section of 20 years aged human tooth showing thin cementum (C) which covers root dentin (D). It is separated from the dentin by the dentino-cementum junction (J). (Ground section X40).

Fig. (2) : Transverse ground section of 50 years aged human tooth showing moderately thickened cementum (C) in comparison to the previous age. There are two types of cementum, cellular with lacunae ( $\uparrow$ ) and acellular ( $\uparrow$ ) with no visible cells. Area of dentin (D) can be seen below the cementum.

(Ground section $X 40$ ).

Fig. (3) : Longitudinal ground section of 80 years aged human tooth, at the middle third of the dental root, showing more thickened cementum $(\mathrm{C})$ in comparison to the previous two ages. This cementum layer covers the entire surface of the dental root and it is of uneven thickness. Externally, bundles of collagen fibers of the periodontal ligament $(\mathrm{P})$ can be seen above the cementum. Internally, area of dentin (D) can be seen below the cementum and the dentino-cementum junction ( $\mathrm{J}$ ) separates it from the cementum. The location of cellular $(\uparrow)$ and acellular $(\uparrow \uparrow)$ cementum is not definite. Cellular cementum is more frequent on the apical half (to the left) whereas the acellular cementum predominates on the coronal half (to the right) of the root. Layers of both can be seen alternate in any pattern.

(Ground section X40). 


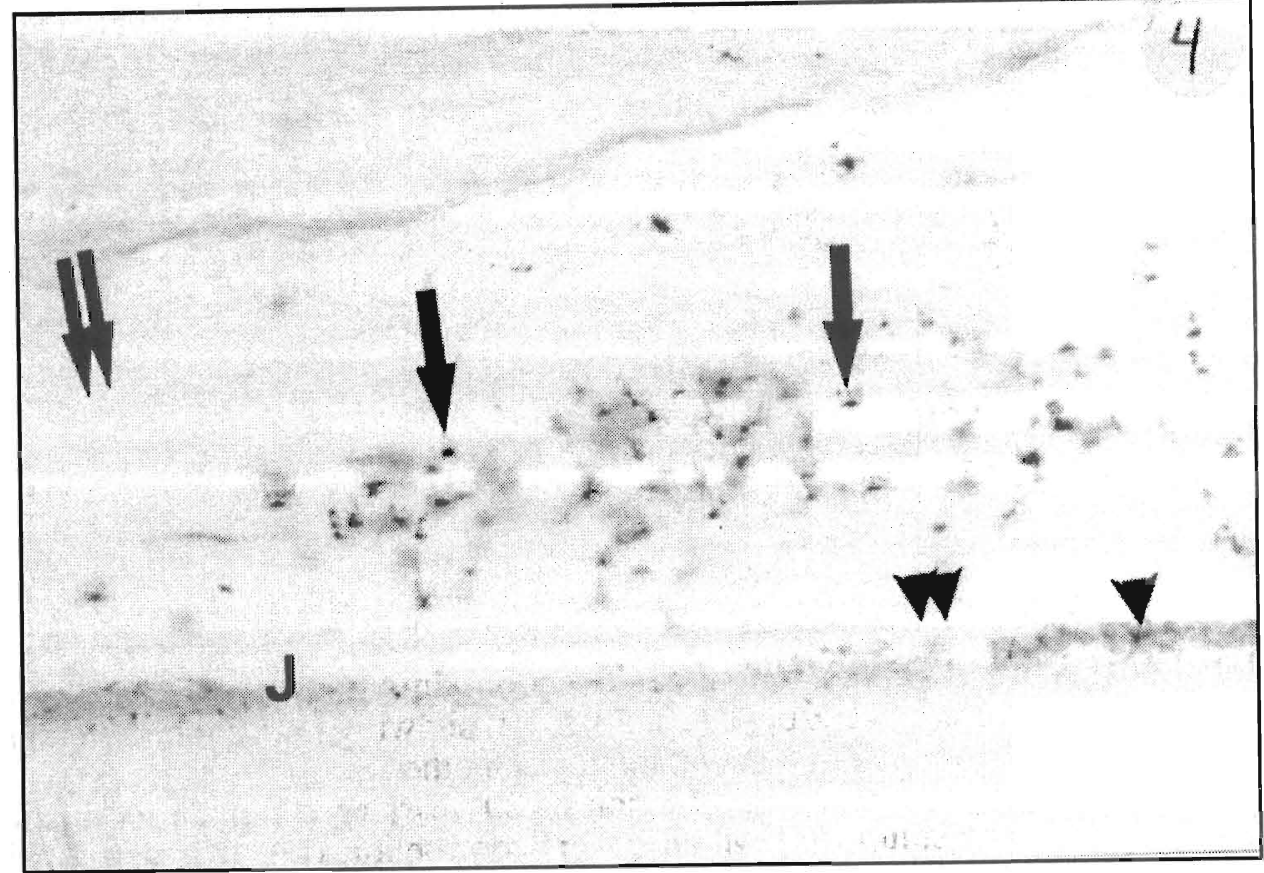

Fig. (4) : Higher magnification of the previous longitudinal ground section of 80 years aged human tooth illustrating acellular cementum on surface of cellular cementum. The cellular cementum appears with multiple lacuinae ( $\uparrow$ ) filled with (spiderlike) cementocytes. The acellular cementum $(\uparrow \uparrow)$ can be seen with very faint refractile incremental lines which can not be counted. The dentino-cementum junction (J) appears in the form of granular layer ( $*)$, which can be seen just line the surface of the dentin, and thin structureless hyaline layer $(\leftarrow+)$, which seen peripheral to the granular layer and separates it from the cementum. (Ground section X100). 


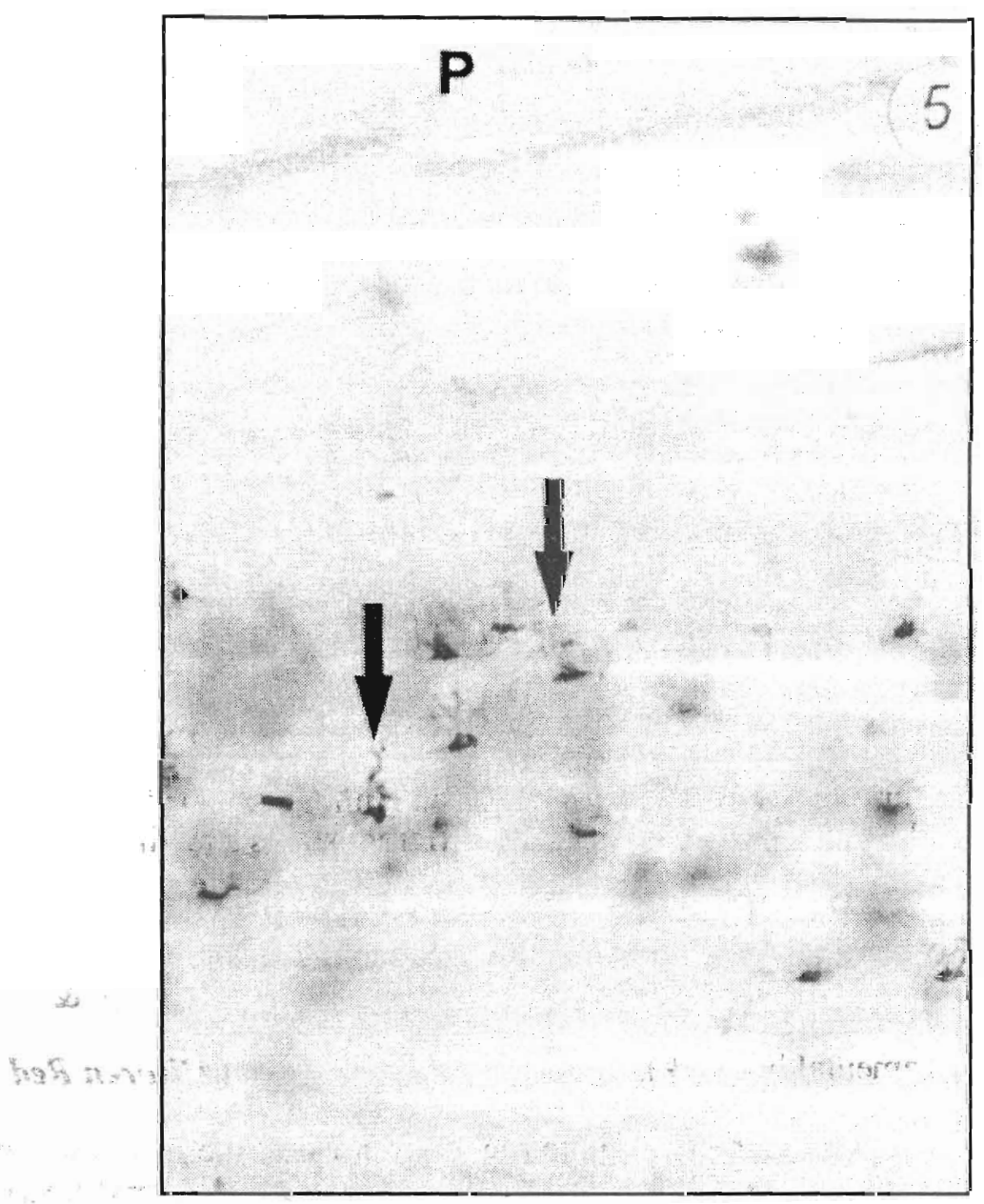

Fig. (5): Higher magnification of the cementocytes in the previous longitudinal ground section of 80 years aged human tooth showing numerous cell processes (Canaliculi) ( $\mathbf{\uparrow}$ ) radiating from the bodies of the cementocytes in the lacunae and directed preferentially towards the periodontal ligament $(\mathrm{P})$.

(Ground section X 200). 


\section{Hassan \& Shehab}

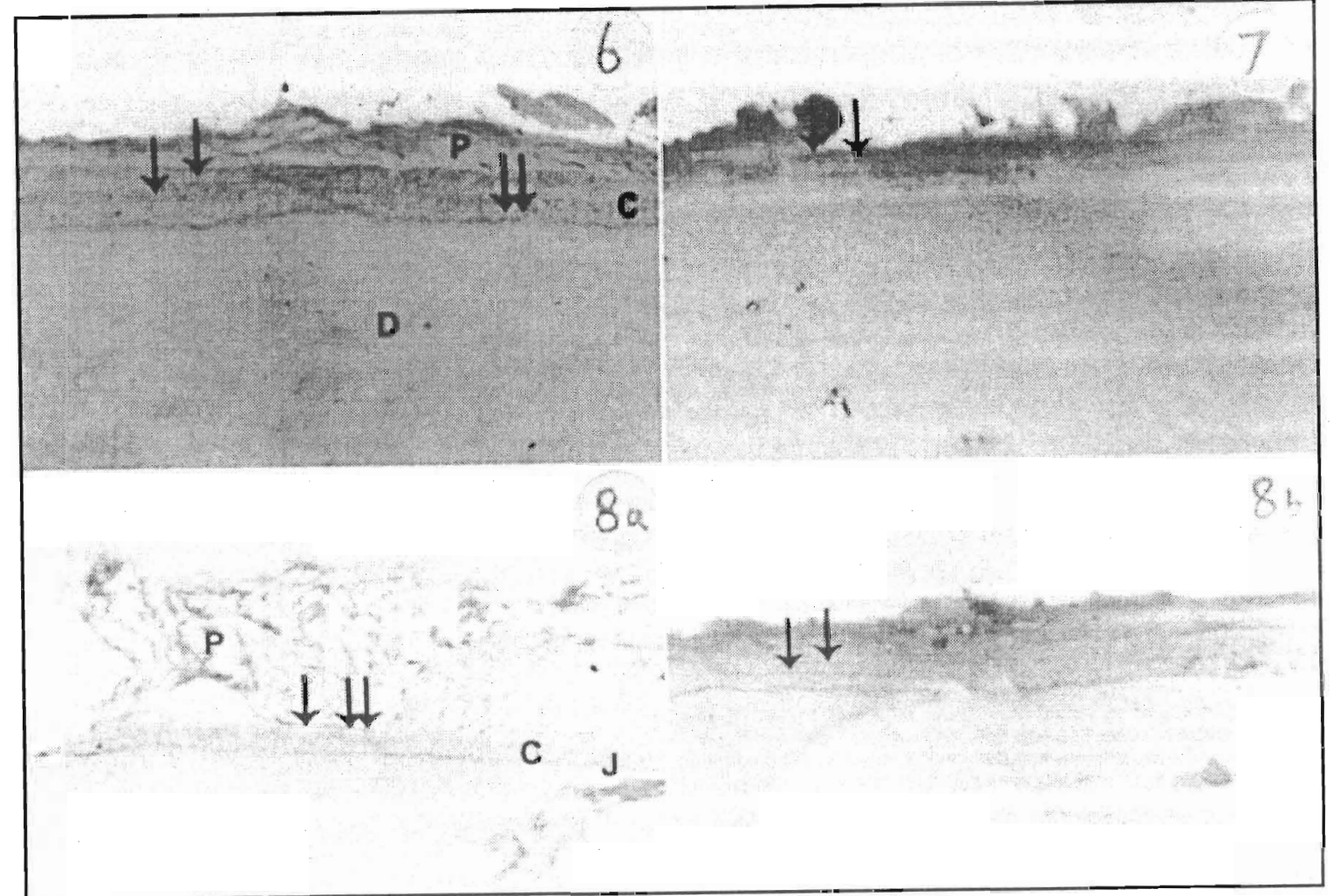

Plate (II): Light photomicrographs of decalcified sections in mandibular first premolar human tooth aged twenty (20) years old with different stains showing:

Fig. (6) : An area of cementum (C) lies between periodontal ligament (P) and dentin (D). The dentino-cementum junction appears as a line ( $\uparrow)$. Two incremental lines ( $\uparrow$ ) can be observed.

$(H \& E \quad X 200)$

Fig. (7) : Two incremental lines ( $\uparrow$ ).

(Alizaren Red X200)

Fig. (8a) : From the dentino-cementum junction (J) outward, there are three different layers can be encountered, first calcified cementum (C), next a strip of cementoid ( $\uparrow)$, and finally a layer of cementoblasts $(\uparrow \uparrow)$. The cementoblasts are located between the inserting fibers of the periodontal ligament (periodontal connective tissue) (P).

Fig. (8b) : Two incremental lines ( $\uparrow)$. 


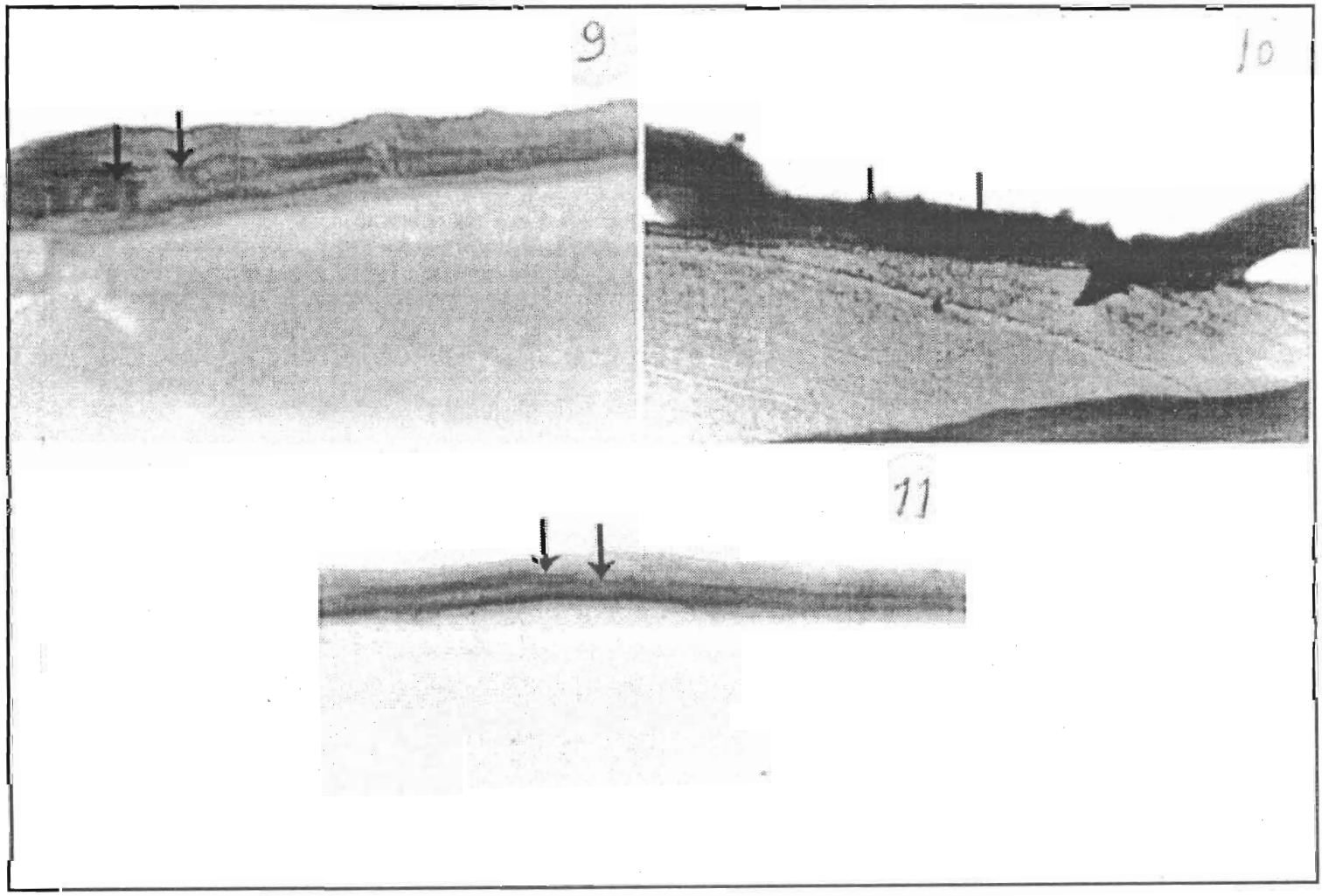

Plate (III) : Light photomicrographs of decalcified sections in mandibular first premolar human tooth aged fifty $(50)$ years old with different stains showing:

Fig. (9) : Two incremental lines ( $\uparrow$ ).

$(H \& E \quad X 200)$

Fig. (10) : Two incremental lines ( $\uparrow)$.

(Alizaren Red X200)

Fig. (11) : Two incremental lines ( $\uparrow$ ).

(Cresyl Violet X200) 


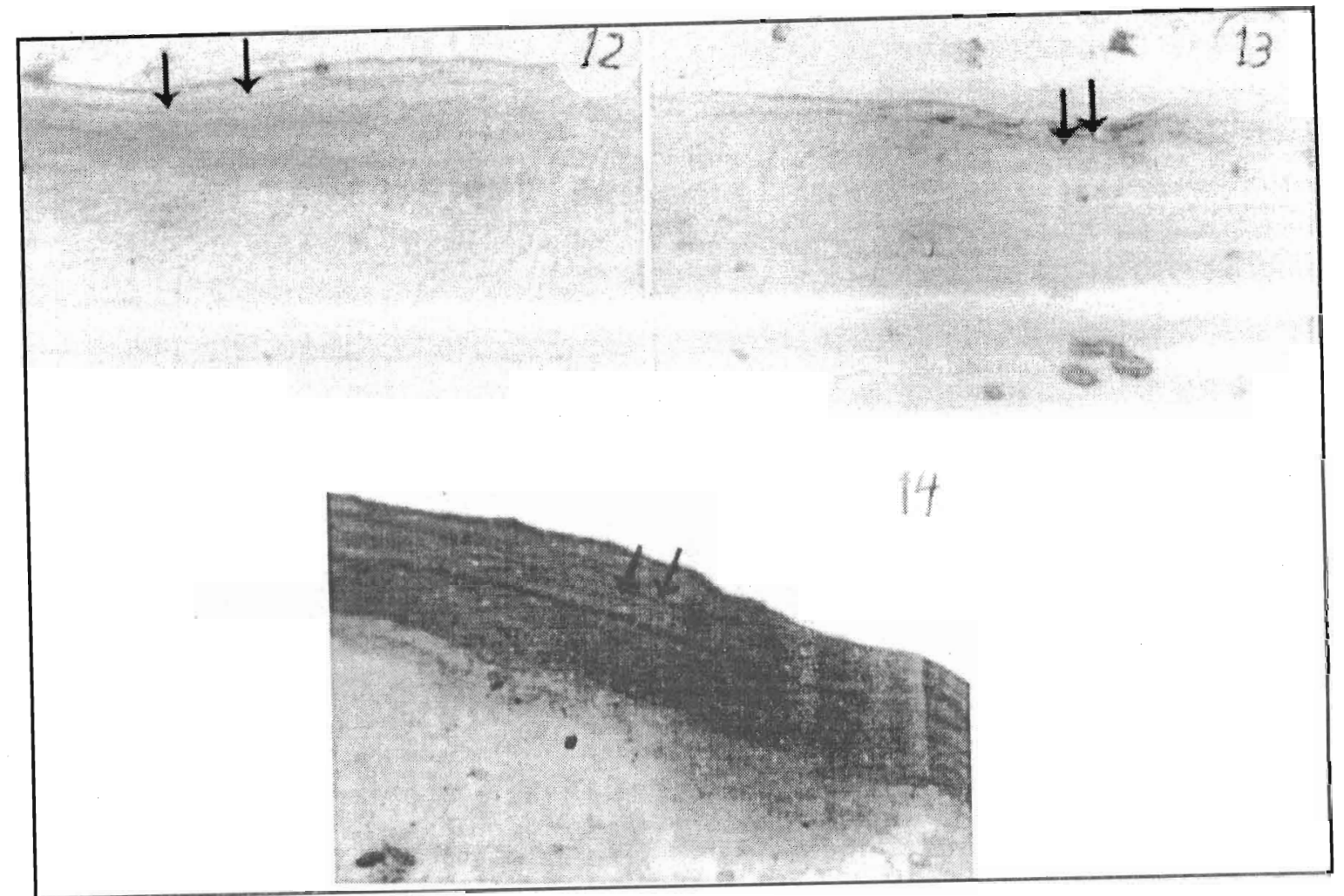

Plate (IV) : Light photomicrographs of decalcified sections in mandibular first premolar human tooth aged eighty $(80)$ years old with different stains showing:

Fig. (12) : Two incremental lines ( $\uparrow$ ). Note that the incremental lines at the surface are more easily defined than the deep one.

$(H \& E \quad X \quad 200)$

Fig. (13) : Two incremental lines ( $\uparrow$ ).

(Alizaren Red X 200)

Fig. (14): Two incremental lines ( $\uparrow$ ).

(Cresyl Violet X 200) 


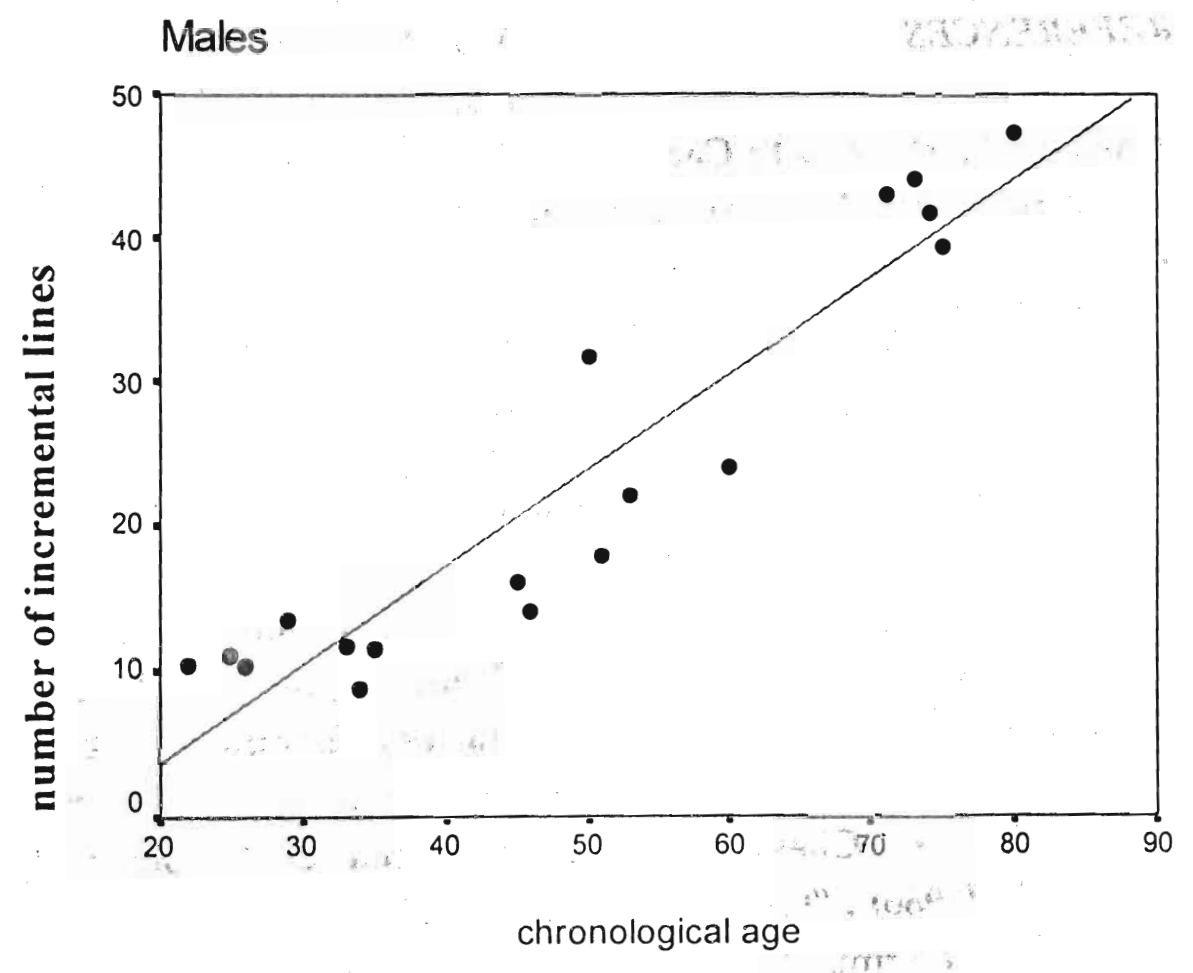

Fig. (15) : Scatterplot of chronological age versus number of incremental lines among males.

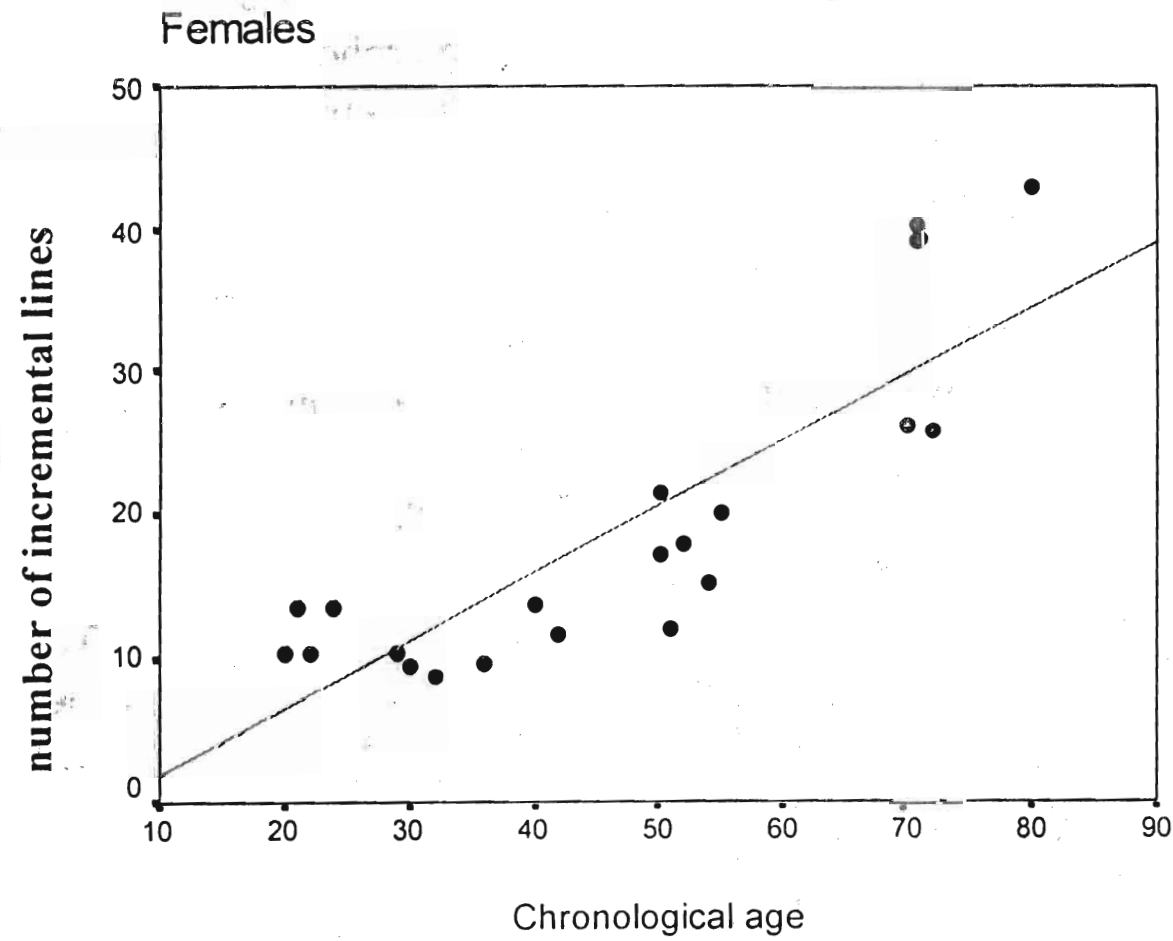

Fig. (16) : Scatterplot of chronological age versus number of incremental lines among females. 


\section{REFERENCES}

Azorit, C.; Analla, M.; Hervas, J.; Carrasco, R. and Munoz-Cobo, J. (2002) : "Growth marks observation preferential techniques and teeth for aging of Spanish Red Deer". Anat. Histol. Embryol., 31 (5) : 303 - 307.

Bhaskar, S. N. (1991) : Cementum. In : Oral Histology and Embryology. 11 $11^{\text {th }}$ ed., Baltimore, Boston, Chicago, London and Toronto, P.P. 180 - 202.

Charles, D. K.; Condon, K.; Cheverud, J. M. and Buikstra, J. E. (1986) : "Cementum annulation and age determination in homo sapiens. I. Tooth variability and observer error". American Journal of Physical Anthropology, 71(3): 311- 320.

Condon, K.; Charles, D. K.; Cheverud, J. M. and Buikstra, J. E. (1986) : "Cementum annulation and age determination in Homo sapiens. II. Estimates and accuracy". American Journal of Physical Anthropology, 71(3):321 - 330 .

Drury, R. A. B. and Wallington, E. A. (1980) : Preparation and fixation of tissue, general staining procedures, bone and decalcification. In : Carlton's Histological Technique. $5^{\text {th }}$ ed., Oxford University Press. Oxford, New York, Toronto. Ch: 3, 7, \& 11., P.P. 41-56, 125-142, 199-218 \& P. 379.
Horobin, R. W. and Bancroft, J. D. (1998) : Troubleshooting Histology Stains. Churchil Livingstone, New York, London and Tokyo, P. $18 \& 48$.

Jankauskas, R.; Barakauskas, S. and Bojarun, R. (2001) : "Incremental lines of dental cementum in biological age estimation". Homo., 52 (1): 59 - 71.

Kagerer, P. and Grupe, G. (2001) : "Age at death diagnosis and determination of life-history parameters by incremental lines in human dental cementum as an identification aid". Forensic Sci. Int., 118 (1): 75-82.

Kolltveit, K. M.; Solheim, T. and Kvaal, S. I. (1998) : "Methods of measuring morphological parameters in dental radiographs". Forensic Sci. Int., 94:8795.

Kvaal, S. and Solheim, T. (1989) : "Fluorescence from dentin and cementum in human mandibular second premolars and its relation to age". Scand. J. Dent. Res., 97:131-138.

Kvaal, S. and Solheim, T. (1995) : "Incremental lines in human dental cementum in relation to age". Eur. J. Oral Sci., 103(4): 225-30.

Kvaal, S. I.; Solheim, T. and Bjerketvedt, D. (1996) : "Evaluation of prepara- 
tion, staining and microscopic techniques for counting incremental lines in cementum of human teeth". Biotech. Histochem., 71(4):165-72.

Lipsinic, F. E.; Paunovich, F.; Houston, G. D. and Robinson, S. F. (1986) : "Correlation of age and incremental lines in the cementum of human teeth". J. Forensic Sci., 31: 982-989.

Miller, C. S.; Dove, S. B. and Cottone, J. A. (1988) : "Failure of use of cemental annulations in teeth to determine the age of humans". J. Forensic Sci., 33(1): 137-143.

\section{Moss-Salentijn, L. and Hendricks-} Klyvert, M. (1990) : Cementum and alveolar bone. In : Dental and Oral Tissues. An Introduction. $3^{\text {rd }}$ edition, Lea and Febiger, Philadelphia, London, P.P. 261-268.

Naylor, J. W.; Miller, W. G.; Stokes, G. N. and Stott, G. G. (1985) : "Cemental annulation enhancement: a technique for age determination in man". Am. J. Phys. Anthropol., 68(2):197-200.

Petrie, A. and Sabin, C. (2005) : Medical Statistics at a Glance. $2^{\text {nd }}$ ed., Blackwell publishing, P.P. 405-410.

Rao, N. G. and Rao, N. N. (1998) : "CCTV study of cemental annulations in determining the age from single tooth". Indian J. Den. Res., 9(2): 41-5.
Renz, H.; Schaeer, V.; Duschner, $H$. and Radlanski, R. J. (1997) : "Incremental lines in root cementum of human teeth: An approach to their ultrastructural nature by microscopy". Adv. Dent. Res., 11 (4):472-477.

Roesing, F. W. and Kvaal, S. I. (1998) : Dental age in adults. A review of estimation methods. In : Dental Anthropology. Fundamentals, Limits, and Prospects. Alt Roesing, K.W.; Teschler-Nicola, M. (Eds.) Springer Wien, P.P.443 - 468.

Solheim, T. (1990) : "Dental cementum apposition as an indicator of age." Scand.J.Dent.Res., 98:510-9.

Sousa, E. M.; Stott, G. G. and Alves, J. B. (1999) : "Determination of age from cemental incremental lines for forensic dentistry". Biotech. Histochem., 74(4): 185-193.

Stein, T. J. and Corcoran, J. F. (1994) : "Pararadicular cementum deposition as a criterion for age estimation in human beings". Oral Surg. Oral Med. Oral Pathol., 77(3):266-70.

Thome, H. and Geiger, G. (1997) : "Comparison of two methods of age determination in teeth of known age from wild Carnivores". Anat. Histol. Embryol., 26 (2): 81-84.

Wittwer-Backofen, U.; Gampe, J. and 
Vaupel, J. W. (2004) : "Tooth cementum annulation for age estimation: results from a large known-age validation study". Am.

J. Phys. Anthropol., 123(2): 119-29. 


\title{
دراسة نسيجية قياسية لنطاء الأسنان العظهى واوتباط النطوط الإضافية هع العهر في الهصريين العنان
}

\author{
المشتركون في اليتث \\ د. نيفّبن أهمسد \\ * من أتسام الطب الشرعى والسيموم والتشريح والأجنــة \\ كلية الطب - جامعة طبطـا
}

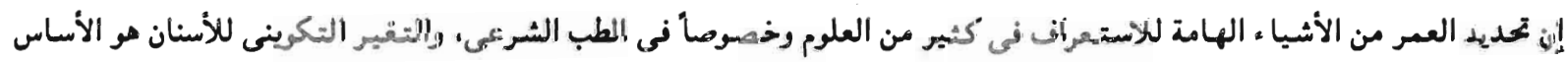

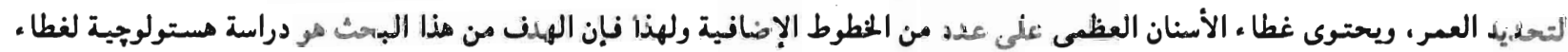

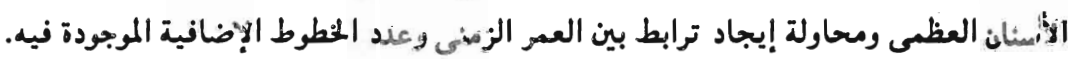

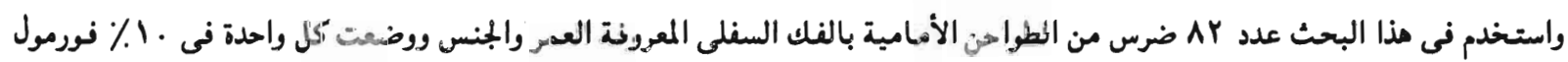

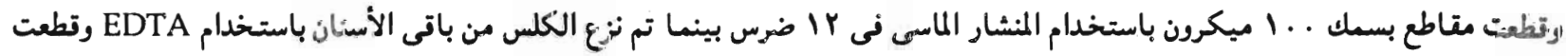

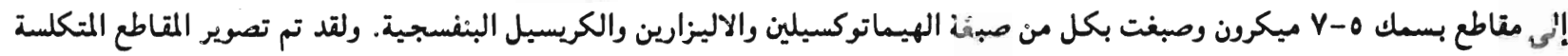

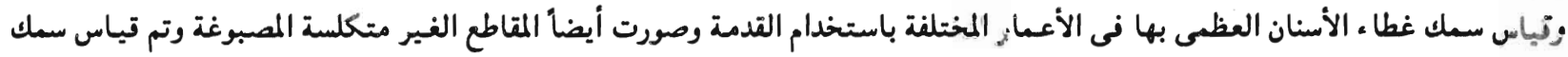

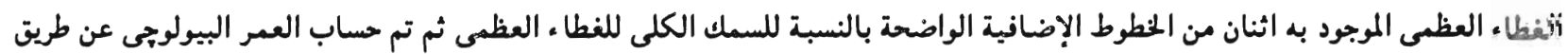

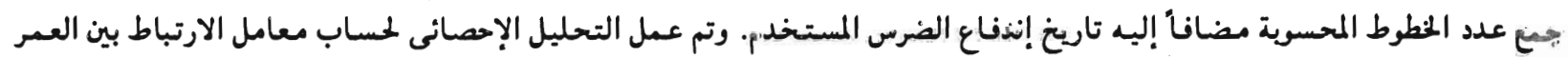

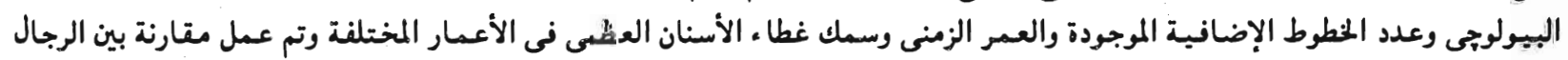

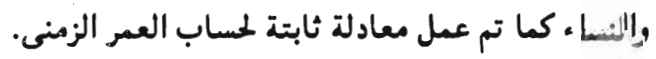

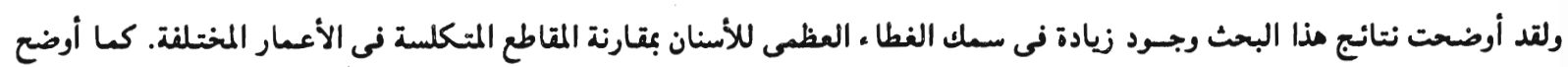

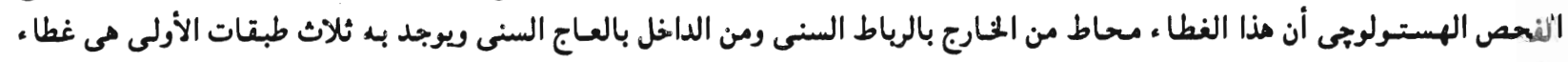

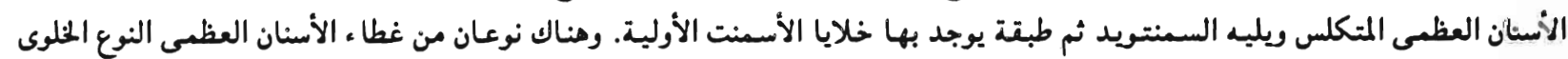

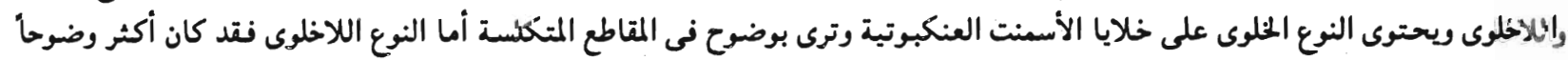

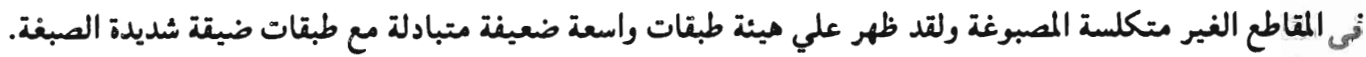

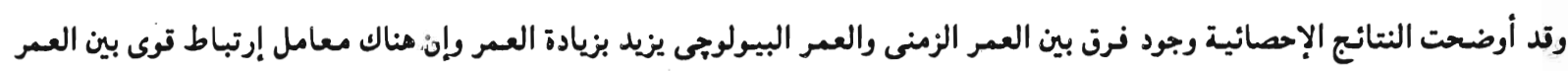

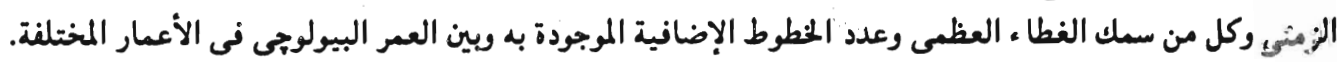

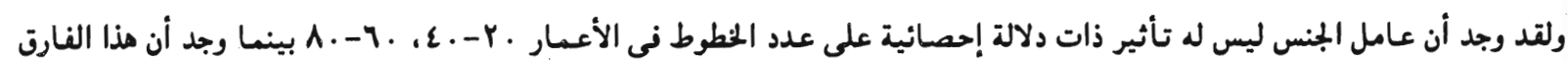

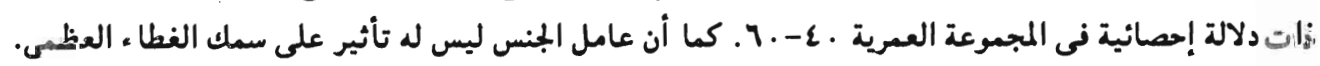

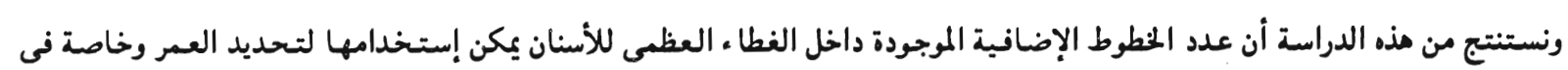
الهياكل العظمية المتنتتة. 


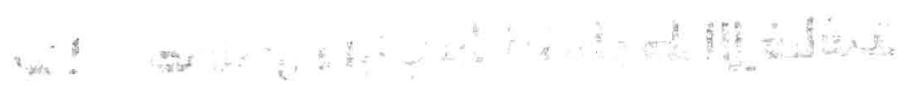

